\title{
Análisis de la carta papal Mulieris Dignitatem a partir de la perspectiva de la teología feminista
}

\author{
Ana Ruth Chinchilla Castillo*
}

\begin{abstract}
RESUMEN
El artículo propone un análisis de la Carta Mulieris Dignitatem, a partir de la teología feminista, particularmente desde el modelo kyriarcal que propone Elizabeth Shüssler. El análisis toma como base dos estructuras sociales que son pilares fundamentales en el documento papal: el matrimonio y la maternidad que se concretan en la metáfora de María. La figura de María se retoma por parte de la biblista Tames, cuyo aporte se incorpora también a este análisis. Se concluye que efectivamente el discurso eclesiástico está teñido de un fuerte contenido kyriarcal.
\end{abstract}

Palabras clave: Modelo Kyriarcal, teología feminista, matrimonio, maternidad, mujer.

\section{ABSTRACT}

This article provides an analysis of the document Mulieris Dignitatem based on the Feminist Teology approach -the kyriarchal based model that Elizabeth Schüssler presents. The analysis is based on two main social structures which are the fundamentals of Mulieris: marriage and motherhood. These are specified in the metaphor of Mary. Her image is retrieved by Tames, biblical scholar, whose input is also incorporated in this paper. It is conclusive that actually the discourse of the Catholic Church includes strong kyriarcal elements.

Keywords: Kyriarcal model, feminist teology, marriage, motherhood, woman.

Licenciada en Docencia con énfasis en Inglés, UNED. Egresada de la Maestría en Teología Católica, UNED. 
Las sociedades han sido testigos de cambios radicales y relevantes en los patrones económicos, sociales, políticos, científicos y de producción. En el campo político hemos visto modelos que surgieron y se han desvanecido, o transformado como respuesta precisamente a esta permanente mutación. Algunos esquemas ultraconservadores han tenido que modificar su práctica con el fin de no desaparecer. Sectores de la población, considerados como "minorías", han librado fuertes luchas para lograr cambios de suma trascendencia. Podemos mencionar, entre otras, las luchas libradas por Martin Luther King, en los Estados Unidos, por la igualdad en los derechos de la población de color en ese país. Es el caso también del derecho al sufragio femenino, lucha que se libró en los siglos XIX y XX en muchos países del mundo. En Costa Rica este derecho no fue posible sino hasta el año 1949; aunque en Latinoamérica ya las mujeres de Uruguay -en forma vanguardista- ostentaban tal derecho desde 1917. Poco a poco, las poblaciones consideradas como "minorías", y en particular la población femenina, se han abierto espacios en diferentes campos de la sociedad: economía, política y religión; pero estos pasos que han dado no han sido fáciles.

Específicamente, en el campo teológico, las mujeres han hecho importantes aportes con una propuesta teologal diferente, alternativa. Las décadas de los setenta y los ochenta constituyeron terreno fértil para observar incipientes y modestas posturas para romper el modelo patriarcal y eurocentrista que -hasta ese momento-había dominado la Iglesia. Junto a los teólogos de la liberación se escuchan también voces femeninas como las de Irene Foulkes y Elizabeth Schüssler; desde la diversidad latinoamericana hacen sonar su voz Ivone Gebara en Brasil, Cora Ferro Calabrese de Argentina y Elsa Tamez, teóloga mexicana, para citar algunos nombres.

Es así como en el caso de la Iglesia Católica, ésta ha tenido igualmente que acoplarse a los vientos de cambio y a las demandas de las sociedades. A partir del Concilio Vaticano II se operan transformaciones importantes, ya que es preocupación del Magisterio adaptar la disciplina eclesiástica a las necesidades de los tiempos, según se expresa en los objetivos del Concilio. La Iglesia es consciente de la imperiosa necesidad de ver el rostro de Dios en el individuo pobre, desposeído, marginado y sin voz. Pero, ¿es posible lograr un abordaje de estas realidades desde una sola perspectiva teologal? El discurso teologal feminista ofrece alternativas para enriquecer este acercamiento con el aporte de diversas perspectivas. Se podrían entonces abordar fenómenos socio-culturales desde la perspectiva de la teología feminista, o de la teología de la liberación, o desde las teologías latinoamericanas. 
Para los contextos latinoamericanos que han sido escenarios históricos de fuertes y sangrientos procesos de colonización, resulta desafiante la propuesta que hace la teología feminista al abordaje de asuntos como la interpretación bíblica, la igualdad del apostolado y el papel de la mujer dentro de la Iglesia Católica, entre otros, con una postura que parte de un punto de vista intercultural y diverso para un mundo diferente. Hace un fuerte llamado a un proceso de cambio mediante el recurso religioso para reemplazar patrones de dominación, por dinámicas de justicia; de subordinación, por emancipación; de un cristianismo absolutista, por un cristianismo de diálogo; de un modelo kyriarcal de interpretación que conjuga diversas estructuras de dominación patriarcal, por un modelo ético, político y crítico. Desde la plataforma de la teología feminista se propone una vivencia transformadora de la fe que destierra todo tipo de interpretación subyugante de algunas figuras tradicionales que han dominado el discurso eclesial.

¿Propone el discurso oficial de la Iglesia Católica en Mulieris Dignitatem esta transformación que plantean las teólogas feministas? O, por el contrario, es una propuesta más, centrada en una teología tradicional masculina $\mathrm{y}$-por tanto- cargada de fuertes connotaciones kyriarcales.

Elizabeth Schüssler hace una fuerte crítica a la teología patriarcal, al discurso bíblico en sí y a la hermenéutica tradicionalmente kyriarcal. Esta teóloga católica feminista, reconocida y respetada en el medio por sus investigaciones y publicaciones, aboga por recuperar los aportes que han hecho las mujeres desde la iglesia cristiana primitiva. "¿Puede un salvador varón salvar a las mujeres?" De esta forma, Schüssler (2000:72), al citar a Rosemary Radford Ruether, señala además un problema que considera central de los discursos cristológicos feministas, y critica también la forma en que éstos discursos han sido "contaminados" socialmente, por la forma en que instituciones como la Academia y la Iglesia los han manipulado. Y es que el peligro radica, según Schüssler, en el hecho de que estas dos instituciones utilicen, como práctica hermenéutica bíblica, aquellos postulados que reflejen como un sentido de mundo o realidad únicamente aquello que no atente contra el orden patriarcal socialmente establecido y aceptado. (Schüssler, 2000, p. 72)

Como respuesta, los movimientos y las teologías feministas presentan un nuevo brío transformador en su lucha por mantener vivas la libertad y la visión de equidad. Sin embargo, Schüssler advierte sobre el riesgo de caer en un "regionalismo" cristológico, pues estos movimientos dirigidos a esas clases inferiores y desfavorecidas corren el riesgo de "servir a los intereses de un pluralismo liberal" (2000:26) $\mathrm{y}$-al acercarse a un análisis de los evangelios desde una perspectiva literaria 
feminista- se transforman en lo que ella señala como el "reverso". (Schüssler, 2000 , p. 26) Se da de esta manera un reforzamiento de las divisiones opresivas de clase, raza, género, religión, nación y edad.

Para evitar que la posición feminista se corrompa (por decirlo de alguna manera), Schüssler presenta una posición radical y sugiere una imagen de teología feminista entendida como...

“...agitadora, que constantemente busca desestabilizar los centros, tanto del ethos pretendidamente libre de valores y neutral de la academia, como de la postura dogmática autoritaria de la religión patriarcal. Propongo que las feministas lo hagan reformulando los discursos académicos y eclesiales desde una perspectiva de liberación feminista crítica. Las teólogas feministas no deben ubicar su trabajo teológico en los bordes y los márgenes, sino trasladarlo al corazón mismo de la academia y de la religión". (Schüssler, 2000, pp. 27-28)

Para continuar con su posición, Schüssler se aparta de la definición tradicional de modelos patriarcales y define lo que comúnmente se conoce como relaciones de poder a partir del término "kyriarcado". La teología feminista a partir del kyriarcado es una liberación crítica, pues apoya su análisis sistémico crítico y sus prácticas intelectuales para la generación del saber religioso en las luchas por la liberación y la igualdad de la mujer. Aclara la autora que no privilegia un análisis marxista de clases, sino que busca comprender las estructuras multiplicadoras de la opresión de las mujeres -racismo, explotación de clases, heterosexismo y colonialismo-que determinan y merman nuestras vidas. A diferencia de otras formas de estudios sobre las mujeres o sobre género, su análisis no depende del marco teórico de un dualismo simbólico de género. (Schüssler, 2000, p. 30)

Concluye Schüssler que el individuo se ubica a lo largo de "múltiples coordenadas sociales de raza, clase, género, sexualidad, etnicidad, entre otras" (Schüssler, 2000, p. 30). Es así como el kyriarcado cobra sentido y desplaza al patriarcado, hasta cierta medida. Es así, también, como los discursos cristológicos feministas deben prestar atención a las situaciones de opresión y redireccionar sus esfuerzos hacia la salvación en las luchas por la supervivencia y por el bienestar de las mujeres que viven bajo un modelo kyriarcal de opresión.

La analítica del kyriarcado brinda un instrumento conceptual de análisis en cuatro niveles, para la interpretación de textos androcéntricos cristológicos y tradiciones kyriarcales como construcciones socioreligiosas y culturales, y no como verdades reveladas por Dios.

- Primer nivel: las relaciones sociales referidas a las diferencias de género son construcciones socio-culturales de relaciones de 
dominancia, no simples hechos biológicos dados.

- Segundo nivel: estas relaciones kyriarcales tienen su basamento en el contexto de la democracia kyriarcal griega, mediadas por las tradiciones bíblico-teológicas cristianas y traídas a la post-modernidad por varones (educados, blancos y de clase alta).

- Tercer nivel: la opresión de las mujeres se logra por la socialización individual y la legitimación de los discursos que logran la religión y la academia, con el fin de estandarizar como verdades las tendencias naturalizadoras de sexo y género.

- Cuarto nivel: el discurso bíblico asienta, mediante la interpretación de un proceso lingüísticosimbólico de naturalización del género, un lenguaje androcéntrico que reitera los prejuicios culturales y religiosos, y las relaciones socio-kyriarcales. (2000, pp. 61-67)

La plataforma que propone Schüssler da una perspectiva integral y aborda los fenómenos de la tensión de género como una dinámica relacional de diversos puntos: lingüísticos, antropológicos y socio políticos.

Por otro lado, la posición de la teóloga Irene Foulkes es más conciliadora, en comparación con las ideas "agitadoras" de Schüssler (tal y como ella misma las define, en párrafos anteriores citados en este documento). Foulkes se ha especializado en metodología exegética y en la perspectiva de la mujer en el estudio de la interpretación de los textos. En su obra "Primeros pasos en la relectura bíblica desde la perspectiva de género", abre la discusión al señalar que "no significa lo mismo leer la Biblia hoy, en América Latina, y desde nuestra experiencia como mujeres, que leer la Biblia en otros tiempos y condiciones, y con otros ojos." (Foulkes, s.f., p. 3). En este sentido, concuerdo con la autora pues, a partir de tal postulado, se propone una serie de connotaciones sobre la interpretación de la Biblia y las relaciones que surgen a partir de tal interpretación con la realidad.

El texto no es una pieza estática, es siempre nuevo cada vez que se lee. Cada vez que se aborda la Biblia, desde una perspectiva nueva, ésta tiene cosas nuevas que contar y nuevos aportes que hacer, y se puede corregir o ampliar interpretaciones que se haya hecho con anterioridad.

Foulkes presenta -aunque de una manera más reducida, en comparación con Schüssler- lo que son las relaciones desde una perspectiva de género. Define estas relaciones como el "conjunto de diferencias entre la conducta de varones y mujeres, determinado por nuestra cultura" que hacen que el hombre y la mujer "experimenten el mundo de manera 
diferente y desigual" (Foulkes, s.f., p. 6). Al citar a Cora Ferro (teóloga feminista de origen argentino), Foulkes coincide con Schüssler al referirse a las relaciones del sistema sexo-género:

...las mamás y los papás, así como la escuela, la iglesia y los medios de comunicación, se encargan de moldearnos para que nos comportemos de la manera que se considera apropiada para nuestro sexo. Esta conducta no la dicta el sexo biológico de la persona... La sociedad se encarga de reforzar este aprendizaje durante toda nuestra vida. (Foulkes, s.f., p. 6)

Este es un complejo proceso de subjetivación del individuo mediante mecanismos socialmente reconocidos e institucionalizados que en el discurso de diferencia de género se reduce a una función biológica. Esta perspectiva se retoma más adelante en la crítica que planteo a la figura del matrimonio y la maternidad en el discurso papal.

Foulkes, al igual que Schüssler, considera que el error histórico y universal de la teología patriarcal radica en que la perspectiva masculina es elevada a imperativo universal y natural en su apreciación del mundo y de lo sobrenatural. El problema "no es representar a Dios como Padre, sino haberlo convertido en la metáfora raíz para el cristianismo, reemplazando el mensaje del reino de Dios por un mensaje de patriarcalismo" (Russell, 1997, p. 93).
Foulkes cuestiona, finalmente, si "la teología elaborada durante siglos solo por varones incorpora adecuadamente la perspectiva de las mujeres". (Foulkes, s.f., p. 7).

Esbozadas las postulaciones teologales que servirán de base, se aborda entonces la Carta Mulieris Dignitatem de S.S. Juan Pablo II sobre la dignidad y la vocación de la mujer con ocasión del Año Mariano. Se resalta la tremenda importancia del rol de María como fuente de inspiración, como modelo a seguir para elevar la dignidad de la mujer. El discurso del Papa señala grandes áreas bajo las cuales se agrupan las características de las mujeres:

- binomio mujer-madre de Dios;

- binomio mujer-imagen de Dios;

- binomio Eva-María;

- relación Jesucristo-mujer;

- binomio maternidad-virginidad;

- binomio Iglesia-mujer esposa de Cristo.

Este documento se inserta en un ambiente de lucha continua por la paz. El período del Papa Juan Pablo II se caracterizó por ser fecundo y largo. Tuvo un fuerte impacto en los medios de comunicación masiva, 
pues el Papa se convirtió en una figura pública de fuerte presencia mediática. No obstante, en contraste con esto, el Papa mantuvo una posición de endurecimiento del proceso de silenciamiento de los líderes católicos de América Latina, Asia y África (Ventura, 2005).

Otra crítica que se le achaca, es su posición radical antireformista al interior de la Iglesia Católica. Esto le hizo enfrentar momentos de crisis pues sus fieles le reprochaban por falta de diálogo y por la forma en que trató los asuntos relacionados con los derechos humanos en general y de las mujeres, en particular. Su rotunda negativa al acceso de las mujeres al sacerdocio y su negativa a tratar los temas relacionados con la moral sexual son ejemplos de su escaso diálogo con las sociedades.

El marco referencial de interpretación por niveles que expone Shüssler servirá de orientación para el análisis que presento de la Carta Papal, el cual se basa en la crítica de dos figuras institucionalizadas socialmente y que reproducen en su concepción y en su práctica elementos kyriarcales: el matrimonio y la maternidad -entendida ésta última como el rasgo biológico que, a partir de la santidad matrimonial, permite no solo la reproducción humana, sino la realización de la mujer y la consagración de la dignidad de la mujer.

\section{Reforzamiento de la figura subyugante del matrimonio o de las uniones a figuras masculinas}

El tema de la dignidad es traído en forma recurrente en el documento papal a partir de una plataforma de complementariedad, de ayuda recíproca. El binomio Adán-Eva se reproduce en el texto de Mulieris Dignitatem mediante la unión de María con el plan salvífico divino. Los procesos de subjetivación de la mujer como individuo y su valor único, expresados en dicho documento, contradicen las mismas palabras de Juan Pablo II en su Carta Encíclica Centesimus Annus cuando afirma que al hombre (entiéndase macho y hembra) se le ha conferido ya de por sí una dignidad incomparable y un valor único en razón de haber sido creado a imagen y semejanza de Dios. ¿Por qué entonces la dignidad de la mujer en función de su unión complementaria con el hombre?

Esta idea de "ayuda recíproca" mencionada antes se refleja muy bien en el capítulo 2 del Génesis. "Indica que el matrimonio es la dimensión primera $y$, en cierto sentido, fundamental de esta llamada... Basándose en el principio del ser recíproco "para" el otro en la "comunión" interpersonal, se desarrolla en esta historia la integración de la humanidad misma, querida por Dios, de lo "masculino" $y$ de lo "femenino". (2004, p. 9) 
En vista de que la mujer tiene una tendencia natural a convertirse en esposa, según lo indica el texto papal más adelante, le presenta una opción más de unión en caso de que desee mantenerse virgen: unirse con Cristo. Esta es una vinculación, una idea de complementariedad espiritual.

La natural disposición esponsal de la personalidad femenina halla una respuesta en la virginidad entendida así. La mujer, llamada desde el "principio" a ser amada y a amar, en la vocación a la virginidad encuentra sobre todo a Cristo... Se da al Esposo divino y esta entrega personal tiende a una unión de carácter propiamente espiritual: mediante la acción del Espiritu Santo se convierte en "un solo espíritu" con Cristo-Esposo (pág. 33).

Desde esta óptica, reitero que entonces resulta imposible para la mujer, como sujeto, pensarse fuera de los ámbitos de este concepto de comunión que sólo se logra a través de la unión con una figura masculina: en matrimonio con un hombre, o en unión espiritual con Cristo. La realización y la dignidad de la mujer, como sujeto autónomo de decisión moral (Juan Pablo II, 1991, p. 27) se alcanza únicamente mediante esta unión, la cual la Iglesia la eleva a un plano sobrenatural cuando se refiere a la unión de la mujer con Dios mediante Jesucristo.
¿Cuál sería la posición de la Iglesia ante las mujeres que -por decisión de vida, o por motivos imperativos- permanecen solteras o deciden separarse y llevar una vida independiente? Evidentemente, según Mulieris, serían sujetos invisibilizados.

Hago la salvedad de que no me estoy refiriendo a un eventual estado o condición de pecado o pérdida de la gracia de estas mujeres producto del rompimiento de su vínculo matrimonial (porque de ser así, serían sujetos pecadores); me refiero concretamente a los procesos de subjetivación kyriarcales que la Iglesia impone a la sociedad, fuera de los cuales las mujeres quedarían invisibilizadas.

Es contradictorio que Mulieris Dignitatem, en sus párrafos introductorios, enfatice en el tratamiento especial que la mujer recibe por parte del Cristianismo y del papel preponderante que se le ha dado en la Iglesia. Resalta, por ejemplo, el rol que desempeña la mujer en puestos públicos, de poder y de decisión política. Sin embargo, es precisamente esta Iglesia quien la ha relegado a un rol de complementariedad y ayuda, de autorrealización en función de una figura masculina, como se evidenció anteriormente. Es también esta misma Iglesia quien excluye a la mujer de prácticas sacerdotales y de mayor rango eclesial. 


\section{La maternidad dentro del matrimonio: sublimación del proceso de subjetivación de la mujer}

Es a la luz de la institución del matrimonio como entonces se justifica, según el documento papal, el segundo gran pilar de análisis crítico: la maternidad.

Aunque la Iglesia Católica reconoce diversas realidades y contextos de la mujer, la carta Mulieris Dignitatem insiste en que la plenitud y la realización máxima de la mujer como tal se alcanza a través de la maternidad, esta última entendida como santo resultado del matrimonio.

Ya el Libro del Génesis permite captar, como un primer esbozo, este carácter esponsal de la relación entre las personas, sobre el que se desarrollará a su vez la verdad sobre la maternidad, así como sobre la virginidad, como dos dimensiones particulares de la vocación de la mujer a la luz de la Revelación Divina. Estas dos dimensiones encontrarán su expresión más elevada en el cumplimiento de la "plenitud de los tiempos" (cf. Gál. 4, 4), esto es, en la figura de la "mujer" de Nazaret: Madre-Virgen. (2004, p. 80).

Es innegable el papel de María en el Plan Salvífico de Dios, y esto lo señala atinadamente el Papa: "La mujer se encuentra en el corazón mismo de este acontecimiento salvífico. La autorrevelación de Dios, que es la inescrutable unidad de la Trinidad, está contenida, en sus líneas fundamentales, en la anunciación de Nazaret." (2004, p. 65). Sin embargo, es inquietante que sobre la premisa de la maternidad y de la sumisión de María se estaría obviando el respeto a las diferentes posturas de las personas, a su libertad a elegir como individuos creados a imagen y semejanza de Dios. ¿Dónde quedaría el concepto de de sujeto autónomo de decisión moral? Se evidencia que los procesos de subjetivación de las mujeres serían nulos si no se enmarcan dentro de estos dos pilares fundamentales para la Iglesia: matrimonio y maternidad. Retomo aquí las palabras de Schüssler citadas en este mismo documento con anterioridad al señalar que las relaciones sociales referidas a las diferencias de género son construcciones socio-culturales de relaciones de dominancia, son simples hechos biológicos dados.

Más adelante el Papa afirma lo siguiente:

La descripción "bíblica" habla, por consiguiente, de la institución del matrimonio por parte de Dios en el contexto de la creación del hombre $y$ de la mujer, como condición indispensable para la transmisión de la vida a las nuevas generaciones de los hombres, a la que el matrimonio y el amor conyugal están ordenados: "Sed fecundos y multiplicaos 
$y$ henchid la tierra y sometedla"

(Gén. 1, 28). (2004, p.75).

Así las cosas, aquellas mujeres que decidieron permanecer solteras como opción de vida, o que decidieron no ser madres estarían, atentando -como decía en una oportunidad Schüssler- contra el orden patriarcal "normal" socialmente ejercido, aceptado y, en este caso, normado mediante la exégesis eclesial sobre un texto bíblico.

Inquieta un poco la exhortación que hace el Papa en el siguiente párrafo:

La mujer - en nombre de la liberación del "dominio" del hombreno puede tender a apropiarse de las características masculinas, en contra de su propia "originalidad" femenina. Existe el fundado temor de que por este camino la mujer no llegará a "realizarse" y podría, en cambio, deformar y perder lo que constituye su riqueza esencial. Se trata de una riqueza enorme (...) Por consiguiente, la mujer -como por su parte también el hombredebe entender su "realización" como persona, su dignidad y vocación, sobre la base de estos recursos, de acuerdo con la riqueza de la feminidad, que recibió el día de la creación y que hereda como expresión peculiar de la "imagen y semejanza de Dios.” (2004, p. 92)

No queda claro en el párrafo anterior lo que las mujeres debemos entender por nuestra "originalidad femenina", nuestra "riqueza esencial". No queda claro tampoco si esta "riqueza esencial" diferenciadora se reduce a una condición biológicamente dada a la mujer: la reproducción. Al ser la cita ambigua, podría especularse sobre la existencia de un elemento más allá del rasgo biológico. Una virtud, tal vez, que distingue a la mujer. Si es así, resulta entonces riesgoso caer en el problema que señala Foulkes, cuando apunta que el error de la teología tradicional, de perspectiva masculina, es elevar sus tesituras a imperativos universales y naturales.

Pensemos por un momento que la capacidad de reproducción, esta característica biológica de la mujer es sublimada por una condición volitiva de la mujer: la maternidad. La dignidad de la mujer, entonces, como persona, se mide y se determina en tanto un valor moral que de por sí es institucionalizado por la sociedad.

Existe sobre Mulieris Dignitatem una crítica que realiza María Cristina "Tirsa" Ventura, biblista dominicana, que considero oportuno integrar a este análisis. En 2005, ella se refiere al concepto de igualdad en el discurso papal $y$ al rol de la mujer a partir del enfoque teologal feminista. Para Ventura, Mulieris Dignitatem maneja en general una igualdad fundamental: todos somos hijos de Dios, iguales ante sus ojos; pero con una diferencia específica, básica, que mantiene apartados a los hombres y a las mujeres, diferencia 
que Ventura explica a partir de las siguientes dos ideas fundamentales: el concepto de igualdad, ¿o concepto de complementariedad?, y el rol de la mujer a imagen de María.

\section{El concepto de igualdad, ¿o concepto de complementariedad?}

En el prólogo elaborado por Jutta Burggraf para Mulieris Dignitatem se señala que Juan Pablo II retrocede hasta el libro del Génesis y le da una interpretación nueva, ubicando a Eva no como la tentadora, sino como la pareja de Adán y en su mismo nivel, uno al lado del otro y frente a Dios, con igual dignidad, libertad y responsabilidad. El Papa continúa en su carta e insiste mucho en que el "ser humano es imagen de Dios. Tanto el varón como la mujer son personas, con una interioridad y profundidad propias, con la posibilidad de comprender el mundo, de ser creativos y desarrollarse en libertad" (Juan Pablo II, 2004, p. 22). No obstante, habla de las características de feminidad y masculinidad como complementarias entre sí, "no solo desde el punto de vista físico y psíquico, sino ontológico" (Juan Pablo II, 2004, p. 48).

Surge entonces la inquietud: ¿cómo pueden dos seres iguales ser complementarios a la vez? ¿Cómo se entiende esta contradicción? En este sentido, Ventura propone una posible respuesta al afirmar que la "antigua aserción de inferioridad natural... fue sustituida por el modelo antropológico de complementariedad mutua" (Ventura, 2005), en el que las mujeres no deben apropiarse de características masculinas. Rescata además, Ventura, este modelo de complementariedad mutua que defiende el Papa en su Carta a las Mujeres de junio de 1995, con motivo de la proximidad de la IV Conferencia Mundial sobre la Mujer en Pekín. Veamos:

¿Y qué decir también de los obstáculos que, en tantas partes del mundo impiden aún a las mujeres su plena inserción en la vida social, política y económica?... es urgente alcanzar en todas partes la efectiva igualdad de los derechos de la persona y por tanto igualdad de salario respecto a igualdad de trabajo; tutela de la trabajadora madre, justas promociones en la carrera, igualdad de los esposos en el derecho de la familia, reconocimiento de todo lo que va unido a los derechos y deberes del ciudadano en un régimen democrático. (Juan Pablo II: 1995)

Es la misma Iglesia Católica, no obstante, la que ha negado históricamente el derecho igualitario de la mujer a tomar decisiones en el campo eclesiástico y a servir como sacerdotisa. Es evidente que este párrafo de la Carta a las Mujeres reduce el aporte femenino específicamente a los medios de producción, oportunidades académicas y deberes y derechos conyugales; parece que la Iglesia Católica 
-arbitrariamente- decidió excluirse a sí misma del "régimen democrático".

Sin embargo, al leer la Carta a los Efesios, se puede hallar una justificación de lo anterior. El Papa utiliza metafóricamente la relación que existe entre Jesús y la Iglesia: Jesús es el novio; la Iglesia, la novia. Y sobre esta metáfora es que se justifica la reproducción kyriarcal de que sólo los hombres pueden ser apóstoles, pues es el legado heredado de Jesús y -por tanto- sólo ellos pueden administrar la Eucaristía.

\section{El rol de la mujer a imagen de María}

Las mujeres, tomando como modelo a María, son llamadas a una santidad mayor que la desarrollada por el sacerdocio. María es el modelo a seguir, es el ideal de vocación, pues como virgen y madre, es el símbolo de toda mujer que se llame cristiana. En el celo que Dios ha puesto en confiar su único Hijo a una mujer, todas las mujeres son llamadas, de algún modo, a ser madres de una forma "de maternidad afectiva, cultural y espiritual" (Juan Pablo II, 2004, pp. 49-50). El principio de creación de la mujer se basa en el auxilio; el servicio (recordemos el concepto de complementariedad que se señaló anteriormente) es la inclinación natural de la mujer que, como María, se pone al servicio de Dios. El servicio de la mujer es un servicio de amor.
Responde, sin embargo, Ventura, que el hecho de tomar a María como modelo, con "disposiciones de escucha, acogida, humildad, fidelidad, alabanza y espera" (Ratzinger, 2004) es un esquema extremadamente pasivo $\mathrm{y}$ frustrante, sobre todo para aquellas mujeres que han optado por otras decisiones de vida.

Para Ventura, las incoherencias que se evidencian en Mulieris Dignitatem, al menos alrededor de estas dos ideas, representan un obstáculo para la integridad y la integridad de las mujeres y los hombres en contextos como el nuestro (Latinoamérica) que se ve tan marcado por divisiones de clase, de raza y de género.

Se evidencia después de la lectura de Mulieris Dignitatem un fuerte contenido kyriarcal que domina el discurso de la Iglesia, al menos en figuras institucionalizadas y socializadas como lo son el matrimonio y la maternidad.

Considero que -si existe esperanza de cambio social- no se dará desde las cúpulas (llámese políticas, educativas, religiosas, etc.). La Iglesia, más bien, recrudece su férrea posición a favor de "el orden natural" de las cosas, según lo señala el propio Papa Benedicto XVI en su reciente discurso durante la misa celebrada en Santiago de Compostela, España este 8 de noviembre. Estos cambios se gestarán desde las bases abriendo espacios de reflexión crítica y propositiva. Las mujeres han logrado importantes 
cambios en diversos campos de la sociedad; sin embargo, el proceso de transformación cultural y social es una constante. Falta todavía un largo trecho por recorrer para llegar a un estado de justicia y de igualdad para todas las personas.

\section{Bibliografía}

Chaves, Rónald (2001). La restauración de la posición de la mujer en el reino de Dios. San José, Costa Rica: Producciones Avance Misionero Mundial.

De Lima Silva, Silvia Regina (2001). El territorio de frontera. San José, Costa Rica: Departamento Ecuménico de Investigaciones (DEI).

Foulkes, Irene (s.f.). Primeros pasos en la relectura bíblica desde la perspectiva de género. Consejo Latinoamericano de Iglesias (CLAI) Secretaria familia, mujeres y niños.

Juan Pablo II, Papa (2004). Carta a las mujeres. San José, Costa Rica: Ediciones Promesa.
Juan Pablo II, Papa (1991). Carta Encíclica Centesimus Annus.

Ratzinger, J. (2004) Carta a los obispos de la Iglesia Católica sobre la colaboración del hombre y la mujer, No. 16.

Russell, Letty M. (1997). Bajo un techo de libertad: la autoridad en la teología feminista. San José, Costa Rica: Departamento Ecuménico de Investigaciones (DEI).

Schüssler Fiorenza, Elizabeth (2000). Cristología Feminista Crítica. Jesús, hijo de Miriam, profeta de la sabiduría. Madrid, España: Editorial Trotta.

Sistema de Estudios de Posgrado, Universidad Estatal a Distancia (2008). Antología del curso Teología Latinoamericana Posconciliar: análisis de textos. San José, Costa Rica.

Ventura, Tirsa (2005). Bajo las incoherencias cotidianas y los deseos de comunión participativa. Reflexionando sobre pontificado. En publicación: Pasos No. 119, mayo-junio. Departamento Ecuménico de Investigaciones. San José, Costa Rica. 
